\title{
Complete Fusion of the Maxillamandibular: Report of a Rare Case and Review of the Literature
}

\author{
Hakim Chabbak, Amine Rafik*, Abdessamad Chlihi \\ National Center for Burns and Plastic Surgery, Casablanca, Morocco \\ Email: ${ }^{\text {Aminerafik8@gmail.com }}$
}

Received 15 April 2015; accepted 5 May 2015; published 13 May 2015

Copyright (C) 2015 by authors and Scientific Research Publishing Inc.

This work is licensed under the Creative Commons Attribution International License (CC BY).

http://creativecommons.org/licenses/by/4.0/

(c) (i) Open Access

\section{Abstract}

The maxillomandibular fusion is a very rare condition, with no more than forty cases described in the literature. Adhesions of bone and/or soft tissue between the mandible and maxilla manifest themselves in the inability to open the mouth added to impacts on mandibular growth, nutrition and speech. This condition can be isolated or, when congenital, associated with other anomalies such as cleft lip and palate, aglossia, or Van der Woude syndrome. In the present paper, we report a case of maxillomandibular fusion treated in our department at University Hospital, between February 2011 and June 2014. The case is a congenital maxillomandibular fusion in a two-year-old infant, associated with a syndrome of Van der Woude. We discuss the diagnostic and treatment difficulties on the anaesthetic and surgical levels and the action to be taken to avoid recurrence. To date, some classifications have been suggested in the literature, but there is no standard treatment protocol. Early treatment is necessary to allow freedom of the upper airway, and ensure proper nutrition and good growth of facial bones. The success of surgery is conditioned by an adequate physiotherapy follow-up likely to guarantee the non-recurrence of the lesion.

\section{Keywords}

Congenital Fusion, Maxillomandibular, Syngnathia

\section{Introduction}

The maxillomandibular fusion is a condition characterized by the presence of adhesions of osseous tissue and/or soft tissue between the mandible and maxilla. This condition may be congenital or acquired, isolated or asso-

${ }^{*}$ Corresponding author.

How to cite this paper: Chabbak, H., Rafik, A. and Chlihi, A. (2015) Complete Fusion of the Maxillamandibular: Report of a Rare Case and Review of the Literature. International Journal of Otolaryngology and Head \& Neck Surgery, 4, 220-223. 
ciated with other abnormalities (temporomandibular ankylosis of the mandibular joint, cleft lip and palate, Van der Woude syndrome, etc.) [1]. Through this clinical case, we report diagnostic modalities of this rare disease, treatment difficulties (surgical and anaesthetic) and the action to be taken aiming at reducing the incidence of recurrence.

\section{Case Report}

E. Meriem is a 2-year-old infant admitted to the Plastic Surgery Service in university Hospital for a cleft lip and palate (CLP). The girl is an only child and there are no similar cases in the family. At the age of 7 months, she was hospitalized in another hospital to remedy the CLP but the occurrence of cardiac arrest at the anaesthetic induction, due to the impossibility of intubation, has discouraged the pursuance of the intervention.

At admission, clinical examination reveals a significant limitation of mouth opening with a $0.5-\mathrm{cm}$ mandible, a CLP with fistulas of the lower lip including a Van der Woude syndrome. An X-ray CT highlighted the CLP but has provided no explanation for the limited opening of the mouth. The decision was made to remedy the cleft lip and perform an intraoral examination under anaesthesia. Indeed, it revealed the presence of bilateral maxillomandibular gingival adhesions explaining the mouth opening limitation. A section of these adhesions exposed a 2-cm mandible, which was maintained by the immediate postoperative establishment of a callus. Currently, 4 years later, the initial result was maintained through a regular physiotherapy follow-up (Figure 1).

\section{Discussion}

The maxillomandibular fusion is an extremely rare condition. A review of the literature is difficult because of the variety of classifications: "Congenital fusion of jaws", "Temporo Mandibular Joints Pseudoankylosis and even agnathia"... In 1936, Burket [2] reported the first case of "maxillomandibularsyngnathia" in a patient who also manifested a Temporo Mandibular Joints (TMJ) Pseudoankylosis, a gum fusion and a hemi-facial atrophy.
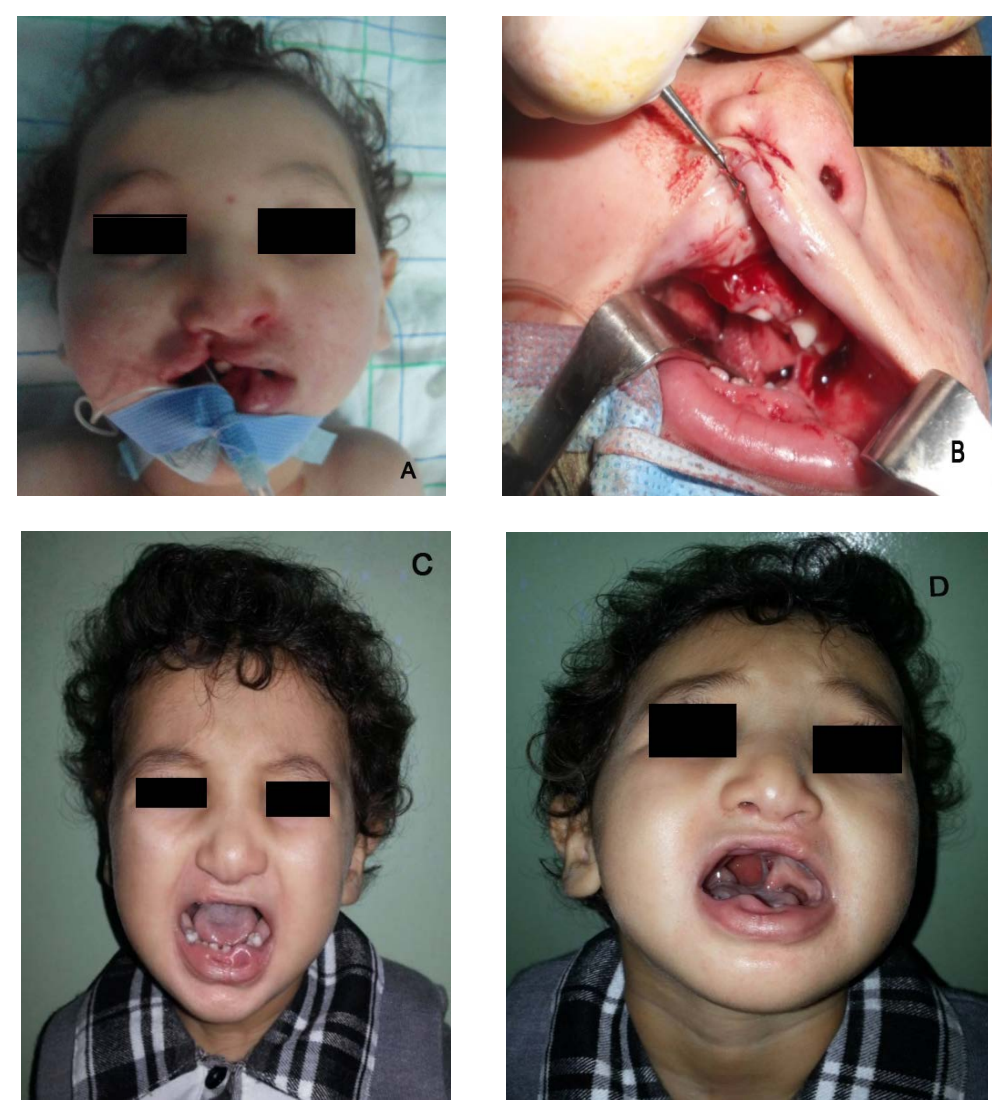

Figure 1. A and B: A 2-year-old child with a cleft palate and the maxillomandibular fusion; $\mathrm{C}$ and $\mathrm{D}$ : The result after 24 months. 
In 2001, Laster et al. [3] stated 24 cases described in the literature. Hegab reported the last cases in 2012 [4]. Hence, forty reported cases.

The causes of congenital syngnathia are not well defined. Some have suggested a persistent oropharyngeal membrane, a constriction by amniotic bands in the area of the development of the first gill arch, violence, and the use of drugs such as high doses of vitamin A during pregnancy [5]. The diagnosis is made when the affected newborns develop respiratory difficulties, then nutrition difficulties, and it is the mouth opening limitation, which is the telltale sign. X-ray or CT can confirm the diagnosis when the fusion affects the bone. An MRI may be indicated when the fusion affects soft tissues. CT imaging gives more information and detects any skeletal dysmorphia [4] [5].

It is difficult to standardize the treatment because the disease is rare, and it is often part of a malformation syndrome [6]-[8]. In all cases, early treatment is essential. A long-term immobilisation would lead to the risk of ankylosis of Temporo Mandibular Joints, making a surgical treatment more complicated [9]. Early surgical release of adhesions is recommended to ensure a normal diet, prevent obstruction of the upper airway, allow normal mandibular function and ensure proper growth [9]. Early intervention is also important to reduce the risk of ankylosis of the ascending rami of mandible to the maxilla and zygomatic complex.

General anesthesia is often difficult. As in the first case where the infant presented problems during the induction that may be probably related to oesophageal intubation. Fiber optic laryngoscopes are required for endotracheal intubation, with careful handling because of the fragility of the mandibular bone with the risk of fracture [10]. Recurrence is a matter of course, along with the need for more interventions. Early, intense and regular physiotherapy follow up reduces this risk. However, it is difficult to establish especially in young patients.

\section{Conclusions}

The maxillomandibular fusion is a rare condition; however, the diagnosis must be carried out after the observation of respiration and nutrition difficulties in newborns, or a mouth opening limitation at an older age. CT or MRI then confirms the diagnosis.

Surgery and anesthesia are subtle and require a knowledgeable team. Early treatment is essential to limit the risk of ankylosis, and early intense and regular physiotherapy treatment reduces the risk of recurrence.

\section{Conflict of Interest}

No conflict.

\section{References}

[1] Daniels, J.S. (2004) Congenital Maxillomandibular Fusion: A Case Report and Review of the Literature. Journal of Cranio-Maxillofacial Surgery, 32, 135-139. http://dx.doi.org/10.1016/j.jcms.2004.01.005

[2] Burket, L. (1936) Congenital Bony Ankylosis and Facial Hemiatrophy. The Journal of the American Medical Association, 106,1719-1722.

[3] Laster, Z., Temkin, D., Zarfin, Y. and Kushnir, A. (2001) Complete Bony Fusion of the Mandible to the Zygomatic Complex and Maxillary Tuberosity: Case Report and Review. International Journal of Oral and Maxillofacial Surgery, 30, 75-79. http://dx.doi.org/10.1054/ijom.2000.0009

[4] Hegab, A., ElMadawy, A. and Shawkat, W.M. (2012) Congenital Maxillomandibular Fusion: A Report of Three Cases. International Journal of Oral and Maxillofacial Surgery, 41, 1248-1252. http://dx.doi.org/10.1016/j.ijom.2012.05.004

[5] Dawson, K.H., Gruss, J.S. and Myall, R.W. (1997) Congenital Bony Syngnathia: A Proposed Classification. The Cleft Palate-Craniofacial Journal, 34, 141-146. http://dx.doi.org/10.1597/1545-1569(1997)034<0141:CBSAPC >2.3.CO;2

[6] Miskinyar, S.A. (1979) Congenital Mandibulo-Maxillary Fusion. Plastic and Reconstructive Surgery, 63, $120-121$. http://dx.doi.org/10.1097/00006534-197901000-00029

[7] Nwoku, A.L. and Kekere-Ekun, T.A. (1986) Congenital Ankylosis of the Mandible: Report of a Case Noted at Birth. Journal of Maxillofacial Surgery, 14, 150-152. http://dx.doi.org/10.1016/S0301-0503(86)80281-8

[8] Rao, S., Oak, S., Wagh, M. and Kulkarni, B. (1997) Congenital Midline Palatomandibular Bony Fusion with a Mandibular Cleft and a Bifid Tongue. British Journal of Plastic Surgery, 50, 139-141. http://dx.doi.org/10.1016/S0007-1226(97)91328-X

[9] Mortazavi, S.H. and Motamedi, M.H. (2007) Congenital Fusion of the Jaws. Indian Journal of Pediatrics, 74, 416-418. 
[10] Bozdag, S., Erdeve, O., Konas, E., Tuncbilek, G. and Dilmen, U. (2011) Management of Serious Isolated Gingival Synechia in a Newborn: Case Report and Review of the Literature. International Journal of Oral and Maxillofacial Surgery, 40, 1428-1431. http://dx.doi.org/10.1016/j.ijom.2011.05.003 